\title{
AC 2011-39: THE EVOLUTION OF ENGINEERING AND ENGINEER- ING TECHNOLOGY EDUCATIONAL PROGRAMS IN THE UNITED STATES
}

\section{George D Ford, Western Carolina University}

Construction Management at Western Carolina University. Dr. Ford worked for over fifteen years in the corporate world in plant engineering and environmental engineering positions and managed numerous construction projects as a plant engineer in the paper, plastics and rubber industries including warehouses, manufacturing buildings and utilities infrastructures.

\section{Aaron K. Ball, Western Carolina University}

Aaron K. Ball is a Full Professor and serves as the Graduate Program Director in Engineering and Technology at Western Carolina University in Cullowhee, North Carolina. He holds a B.S. and an M.S. from Appalachian State University, and earned his doctorate from Virginia Polytechnic Institute and State University. His areas of interests include fluid power, advanced machining, prototyping systems, and applied research. 


\title{
The evolution of engineering and engineering technology educational programs in the United States
}

\begin{abstract}
Since the turn of the century, there have been about the same number of programs in the mechanical, electrical civil, chemical and industrial disciplines to be newly accredited by the Accreditation Board for Engineering and Technology (ABET) in engineering versus engineering technology. According to ABET, these disciplines represent the majority of the total current number of engineering and engineering technology programs they oversee. However, considering only newly accredited programs since 2000 , there have been considerably more engineering programs than engineering technology programs to receive their first review by ABET. In addition, while there have been some small, recent enrollment increases in engineering programs nationwide, these programs typically suffer from low enrollments and high operating costs.

The engineering disciplines which show anticipated job growth greater than graduation rates are environmental, industrial, electronics and mining engineers. A review of the five primary curricular areas of engineering shows four of the five are forecast to graduate nearly 224,000 more engineers than will be needed. Administrators should not initiate programs in electrical, mechanical, civil, or chemical disciplines nor most other disciplines of engineering. Environmental, industrial, electronics and mining engineers are forecast to be the strongest engineering areas in which to invest from a standpoint of jobs available to graduates.

In the engineering technology job fields, all but mechanical engineering technology are forecast to need more graduates than will graduate. Engineering technology degrees will be less risky to start than engineering degrees due to the generally larger student to program ratios.
\end{abstract}

Keywords: engineering enrollment, engineering accreditation, engineering technology enrollment

\section{Introduction}

"Improvise, adapt, overcome" is a credo that engineering and technology educational program administrators at American universities may need to adopt. To maintain the quality of higher education in the United States, administrators must strategically plan to optimize programs which may be successful and discontinue programs which are not successful. They must improvise in a time when public funding of higher education is declining, adapt programs to optimize their operations, and overcome the natural effect of diminished quality which is expected during periods of inadequate operational funding.

"When this recession ends, campuses should not restore funding to every program that has been cut. Instead, they should begin preparing for the next downturn, since, if there has been a single lesson coming out of the last two years, it is that we have not defeated the business cycle" 9 . Newfield also suggests establishing programs that enhance productivity without sacrificing quality. How does an administrator of a higher education program accomplish this task? A natural response is to benchmark the world's top universities, most of which are in the United States, but a review of the financial status of universities on the top twenty list ${ }^{11}$ reveals a general lack of reliance upon public funding. Harvard, Cambridge, MIT, Yale, Cornell rely 
heavily on endowments for operational funding. Yale's endowments, for instance, provided 46 percent of total operating revenue last year ${ }^{5}$. In addition, tuition and fees at the top universities might go as high as their presidents and operating boards wish without impacting the number of students who attend. Administrators on the ground at public universities generally have four options for funding: public funding through their state government; grant funding from the Federal government and private institutions for research; endowments and donations; and tuition.

Public funding of universities by state governments has been flat or falling for more than twenty years ${ }^{9,13}$. State governments generally can no longer be relied upon to provide necessary funding for educational programs when the economy is poor. This was not the case in the 1980s and before ${ }^{3}$. The same principle applies to endowments and donations. When the economy is slow, donations to universities are generally lower ${ }^{8}$. With reduced state funding and lower donations received during hard economic times, obtaining grant funding and raising tuition are the only alternatives for maintaining the stability of educational programs.

Raising tuition is often dependent upon program enrollments. State governments often set enrollment minimums for programs. As an example, North Carolina funds sixteen university campuses based upon a student contact hour model ${ }^{2}$. North Carolina uses four category levels of funding instructional positions:

$$
\begin{array}{ll}
\text { Category I } & 708.64 \mathrm{SCH} \\
\text { Category II } & 535.74 \mathrm{SCH} \\
\text { Category III } & 406.25 \mathrm{SCH} \\
\text { Category IV } & 232.25 \mathrm{SCH}
\end{array}
$$

The Category IV level includes higher priority programs such as engineering and nursing. The lowest category includes English, social sciences, mathematics, and philosophy. For instance, a professor teaching multiple sections of a three credit hour English 101course needs 708.65 divided by 3 which equals about 236 students total, or about 59 students per class if four classes are taught, to justify his position financially. A nursing or engineering professor only needs 78 students or about 20 students per section for four sections. If a program administrator managing an engineering (Category IV) or an engineering technology (Category III) program is facing enrollment levels below the published funding guidelines, tuition increases may be problematic.

Faculty of engineering programs often receive research grants. One Canadian study found that 80 percent of researchers in engineering received funding for research for at least one project versus 55 percent for the faculty in basic medical sciences programs ${ }^{7}$. Administrators must be careful about the research they perform. Newfield ${ }^{9}$ found that "Extramural sponsors of research never pay the full costs of that research... and private sponsors generally require it to pay the most". While research may provide additional funding for operations, this source of funds may also be affected by the economy. In addition, facilities to perform research must be available to the researchers. If facilities are not available, it may be impractical to apply for research grants unless the grant includes funding for the equipment or facilities needed to perform the research. For engineering and engineering technology program administrators, a possible best long term strategy may be to assure program sustainability by providing quality programs which maintain adequate enrollment levels and to apply for research funding from Federal agencies and private sources. 
For the engineering and technology fields, post-secondary educational programs there are several sources of information for an administrator to refer to provide programs with acceptable enrollment levels. The outlook for engineering jobs is positive for the next ten years according to the Bureau of Labor Statistics ${ }^{1}$ and salaries for engineers are typically in the $\$ 80,000$ to $\$ 100,000$ per year range ${ }^{4}$. The Accreditation Board for Engineering and Technology and the Bureau of Labor Statistics provide information which may be used to determine the best program concentrations.

\section{Accreditation Board for Engineering and Technology}

According to their website, the Accreditation Board for Engineering and Technology (ABET) "serves the public through the promotion and advancement of education in applied science, computing, engineering, and technology." They "provide, operate and maintain an independent and objective accreditation system of the highest quality and effectiveness." They accredit engineering programs which may be described as "the art of applying the principles of mathematics and science, experience, judgment and common sense to make things which benefit people. Engineering technology programs are characterized by their focus on application and practice, and by their approximately 50/50 mix of theory and laboratory experience" 6 .

ABET provides statistics about accredited programs. They reported 1964 bachelor degree programs at 397 institutions accredited by the Engineering Accreditation Commission (EAC) as of October, 2009, and 651 associate and bachelor programs at 230 institutions accredited by the Technology Accreditation Commission (TAC). It appears more engineering programs are becoming accredited, while accreditation of engineering technology programs seems to be on the decline. The primary curricular areas of engineering and technology which are accredited are electrical, mechanical, civil, chemical and industrial ${ }^{12}$.

The number of graduates from ABET accredited programs from 2004 to 2009 is shown in Table 1. In 2009 , there were 74,387 bachelor graduates from engineering programs accredited by ABET, about 38 graduates per program on average . During the same period, there were 6044 bachelor graduates from engineering technology programs or about 77 graduates per program, see Table 2.

The number of graduates from engineering technology increased while the number of programs decreased, but the growth in engineering graduates was just over two percent while the number of programs increased by almost seven percent ${ }^{12}$. It appears there are more engineering programs competing for fewer students.

\section{The Bureau of Labor Statistics}

A report published by the Bureau of Labor Statistics (BLS) entitled, "Occupational employment projections to 2018 " provides a point for analysis. In the engineering field, there are forecasted to be 531,300 job openings from 2008 through 2018 due to growth and worker replacement. In the engineering technology field, there are expected to be 124,900 total openings. The BLS categories are slightly different from the ABET categories. 
Table 1: Engineering Graduates from 2004-2009. Source Profiles of Engineering and Technology Colleges, 2009.

\begin{tabular}{|l|r|r|r|r|r|r|}
\hline Bachelor's Degrees & $\mathbf{2 0 0 4}$ & $\mathbf{2 0 0 5}$ & $\mathbf{2 0 0 6}$ & $\mathbf{2 0 0 7}$ & $\mathbf{2 0 0 8}$ & $\mathbf{2 0 0 9}$ \\
\hline Aerospace & 2,232 & 2,371 & 2,722 & 2,788 & 2,930 & 3,057 \\
\hline Architectural & 590 & 722 & 631 & 625 & 646 & 723 \\
\hline Biological/Agricultural & 601 & 635 & 646 & 659 & 623 & 631 \\
\hline Biomedical & 2,019 & 2,410 & 2,917 & 2,969 & 3,237 & 3,644 \\
\hline Chemical & 4,801 & 4,521 & 4,452 & 4,551 & 4,850 & 5,185 \\
\hline Civil & 8,142 & 8,247 & 8,935 & 9,402 & 10,132 & 10,508 \\
\hline Civil/Environmental & & 212 & 291 & 445 & 464 & 558 \\
\hline Computer & 5,838 & 5,455 & 4,901 & 4,046 & 3,808 & 3,394 \\
\hline Computer Science (inside & & & & & & \\
eng.) & 9,156 & 8,419 & 7,330 & 6,446 & 5,964 & 5,652 \\
\hline Electrical & 12,500 & 12,459 & 11,915 & 11,467 & 10,790 & 9,859 \\
\hline Electrical/Computer & 2,700 & 2,924 & 2,825 & 2,425 & 2,216 & 2,194 \\
\hline Engineering (general) & 1138 & 1179 & 1176 & 1246 & 1160 & 1246 \\
\hline Engineering Management & 302 & 303 & 238 & 274 & 331 & 309 \\
\hline Eng. Science \&Eng. Physics & 501 & 383 & 431 & 460 & 472 & 431 \\
\hline Environmental & 576 & 522 & 437 & 454 & 486 & 503 \\
\hline Industrial/Manufacturing & 3790 & 3647 & 3664 & 3503 & 3367 & 3510 \\
\hline Mechanical & 14,182 & 14,947 & 16,063 & 16,701 & 17,324 & 17,375 \\
\hline Metallurgical \& Materials & 817 & 840 & 909 & 963 & 1095 & 1035 \\
\hline Mining & 85 & 92 & 120 & 119 & 153 & 190 \\
\hline Nuclear & 202 & 275 & 342 & 402 & 415 & 378 \\
\hline Other & 2,488 & 2,724 & 2,902 & 2,942 & 3,211 & 3,351 \\
\hline Petroleum & 233 & 315 & 339 & 428 & 496 & 654 \\
\hline Total & $\mathbf{7 2 , 8 9 3}$ & $\mathbf{7 3 , 6 0 2}$ & $\mathbf{7 4 , 1 8 6}$ & $\mathbf{7 3 , 3 1 5}$ & $\mathbf{7 4 , 1 7 0}$ & $\mathbf{7 4 , 3 8 7}$ \\
\hline
\end{tabular}

If a list of common categories is built, a table of forecast job openings versus degrees awarded will result. See Table 3. Observation of the information provided reveals that the number of degrees awarded multiplied by ten, the time period of the forecasts, then there will be more graduates than jobs.

If the table is further consolidated by calculating the growth rate in college graduates based upon historical data, the result will show there are forecast to be more graduates than there will be jobs in most categories, see Table 4. While it is difficult to directly correlate engineering graduation numbers with BLS categories, engineering and technology program administrators should take care when considering new programs or continuing old ones. The subset of programs shown here represent 602,800 jobs of the total anticipated 656,200 . There will be crossover between disciplines, such as 
Table 2: Engineering Technology Graduates from 2003 \& 2009. Source Profiles of Engineering and Technology Colleges, 2009.

\begin{tabular}{|c|c|c|}
\hline Engineering Technology Degrees & 2003 & 2009 \\
\hline Aerospace & 48 & 7 \\
\hline Architectural & 126 & 88 \\
\hline Civil & 479 & 324 \\
\hline Eng. Technology (general) & 683 & 333 \\
\hline Industrial/Manufacturing & 258 & 342 \\
\hline Computer & 223 & 536 \\
\hline Construction & 316 & 795 \\
\hline Other & 1617 & 924 \\
\hline Electrical & 1559 & 1,328 \\
\hline Mechanical & 627 & 1,367 \\
\hline
\end{tabular}

Table 3: Engineering \& Technology Jobs. Source: Bureau of Labor Statistics, 2010

\begin{tabular}{|l|c|c|c|c|}
\hline Employment Title & $\mathbf{2 0 0 8}$ & $\mathbf{2 0 1 8}$ & $\begin{array}{c}\text { Total job } \\
\text { openings } \\
\text { (X 1000) }\end{array}$ & $\begin{array}{c}\text { Awarded } \\
\text { degrees, } \\
\mathbf{2 0 0 9}\end{array}$ \\
\hline Aerospace engineers & 71.6 & 79.1 & 22.3 & 3057 \\
\hline Agricultural engineers & 2.7 & 3 & 0.9 & 631 \\
\hline Biomedical engineers & 16 & 27.6 & 14.9 & 3644 \\
\hline Chemical engineers & 31.7 & 31 & 7.8 & 5185 \\
\hline Civil engineers & 278.4 & 345.9 & 114.6 & 10508 \\
\hline Computer hardware engineers & 74.7 & 77.5 & 23.5 & 3394 \\
\hline Electrical and electronics engineers & 301.5 & 304.6 & 72.3 & 2194 \\
\hline Electrical engineers & 157.8 & 160.5 & 38.9 & 9859 \\
\hline Environmental engineers & 54.3 & 70.9 & 27.9 & 1061 \\
\hline Industrial engineers & 455.2 & 519 & 94.6 & 3510 \\
\hline Mechanical engineers & 238.7 & 253.1 & 75.7 & 17,375 \\
\hline Mining and geological engineers & 7.1 & 8.2 & 2.6 & 190 \\
\hline Nuclear engineers & 16.9 & 18.8 & 5.4 & 378 \\
\hline Petroleum engineers & 21.9 & 25.9 & 8.6 & 654 \\
\hline Aerospace engineering technicians & 8.7 & 8.9 & 1.8 & 7 \\
\hline Civil engineering technicians & 91.7 & 107.2 & 32.8 & 1119 \\
\hline Electrical \& electronic engineering & & & & \\
techs & 164 & 160.4 & 31 & 1328 \\
\hline Industrial engineering technicians & 72.6 & 77.4 & 18.5 & 342 \\
\hline Mechanical engineering technicians & 46.1 & 45.5 & 8.7 & 1367 \\
\hline
\end{tabular}


Totals $602800 \quad 65803$

mechanical engineers performing environmental work, but there will be more engineers than the job market will be able to absorb.

Table 4: Growth of Engineering and Technology Graduates versus Jobs 2009-2018

\begin{tabular}{|l|c|c|c|}
\hline Employment Title & $\begin{array}{c}\text { Total* } \\
\text { Bachelor } \\
\text { Degrees } \\
\mathbf{2 0 0 9 - 2 0 1 8 p}\end{array}$ & $\begin{array}{c}\text { Total Job } \\
\text { Openings } \\
\mathbf{2 0 1 8}\end{array}$ & Surplus \\
\hline Aerospace engineers & 57941 & 22300 & -35641 \\
\hline Agricultural engineers & 6549 & 900 & -5649 \\
\hline Biomedical engineers & 101991 & 14900 & -87091 \\
\hline Chemical engineers & 48722 & 7800 & -40922 \\
\hline Civil engineers & 115820 & 114600 & -1220 \\
\hline Computer hardware engineers & 31802 & 23500 & -8302 \\
\hline Electrical and electronics engrs & 22259 & 72300 & 50041 \\
\hline Electrical engineers & 93408 & 38900 & -54508 \\
\hline Environmental engineers & 9946 & 27900 & 17954 \\
\hline Industrial engineers & 34900 & 94600 & 59700 \\
\hline Mechanical engineers & 202641 & 75700 & -126941 \\
\hline Mining and geological & & & \\
engineers & 2041 & 2600 & 559 \\
\hline Nuclear engineers & 8983 & 5400 & -3583 \\
\hline Petroleum engineers & 13983 & 8600 & -5383 \\
\hline Aerospace engineering techs & 42 & 1800 & 1758 \\
\hline Civil engineering technicians & 25097 & 32800 & 7703 \\
\hline $\begin{array}{l}\text { Electrical and electronic engr } \\
\text { techs }\end{array}$ & 12084 & 31000 & 18916 \\
\hline Industrial engineering techs & 4232 & 18500 & 14268 \\
\hline Mechanical engineering techs & 30402 & 8700 & -21702 \\
\hline Totals & 822841 & 602800 & -220041 \\
\hline & & & \\
\hline & 2500 & \\
\hline
\end{tabular}

*Calculated by taking the number of graduates and applying the average growth rate from historical data and applying the formula $\mathrm{FV}=\mathrm{PV}(1+\mathrm{i})^{\mathrm{n}}$ for each consecutive year.

\section{Recommendations}

The engineering disciplines which show anticipated job growth greater than graduation rates are environmental, industrial, electronic and mining fields. If a review of the five primary curricular areas of engineering which are electrical, mechanical, civil, chemical and industrial is made, four 
of the five are forecast to graduate nearly 224,000 more engineers than will be needed. Administrators should not initiate programs in electrical, mechanical, civil, chemical disciplines or most other disciplines of engineering. Environmental, industrial, electronics and mining fields are forecast to be the strongest engineering areas in which to invest.

In the engineering technology job fields, all but mechanical engineering technology are forecast to need more graduates than will graduate, but it is assumed that the BLS database includes bachelor and associate degrees whereas the ABET database only reports bachelor degrees in engineering technology. Engineering technology degrees will be less risky to start than engineering degrees due to the generally larger student to program ratios observed in the previous discussion. Even given North Carolina's funding model, technology programs make more sense from a management standpoint than does engineering.

The best programs may be combinations of engineering and engineering technology. For instance, environmental, industrial, electronics and mining engineers are forecast to be the strongest engineering curriculums which will provide jobs for graduates. For administrators who want engineering programs at their institutions, initiating a program in one of these areas in coordination with a similar engineering technology curriculum might provide the best of both worlds. Research funded engineering faculty may work in concert with engineering technology faculty teaching well enrolled courses with acceptable student contact hours thereby providing the necessary state funding to maintain both programs. Administrators at each institution could formulate plans which would synergize their programs. For instance, an environmental engineering program might work in concert with a civil engineering technology (CET) program or even a construction management (CM) program for a specific department. The environmental faculty could apply for research grants and the civil and construction programs could support the department with student contact hours. Some lower level engineering courses might even be integrated into the curriculums of the CET or CM programs.

\section{Conclusion}

"When this recession ends, campuses should not restore funding to every program that has been cut. Instead, they should begin preparing for the next downturn, since, if there has been a single lesson coming out of the last two years, it is that we have not defeated the business cycle". Observation of the data included in this paper seems to support this statement. Well funded, "fat" programs will probably never again be the norm. Faculty of engineering and technology programs have an opportunity to steer their own destiny if administrators will create supportive environments.

Engineering and technology faculty should remain open-minded about the possibilities of a future technology worker surplus in their fields. Administrators of these programs should be cognizant of the job security concerns of their faculty should engineering and technology programs be eliminated. Additional study needs to be done of the jobs outlook in specific engineering and technology fields to provide data that will support sound decision making. 


\section{References}

[1] Bureau of Labor Statistics, 2010. Occupational employment projections to 2018. Retrieved from Academic Search Premier database.

[2]Carrigan, S., 2008. Formula Funding, the Delaware Study, and the University of North Carolina.. NEW DIRECTIONS FOR INSTITUTIONAL RESEARCH, no. 140, Winter 2008

[3] Doyle, W. and Delaney, J., 2009. Higher Education Funding: The New Normal. Change July/August 2009.

[4] Electronic Design, 10/22/2009, Vol. 57 Issue 22, p22-29.

[5] Fabrikant, G., 2010. Yale Endowment Gained 8.9\% Last Year.. New York Times, 9/25/

[6] 2010 Fairleigh Dickinson University, School of Engineering and Engineering Technology, (2010). Retrieved on November 25, 2010 from http://alpha.fdu.edu/engineering/seevseet.htm

[7] Larivière,V., Macaluso,B., Archambault, E. and Gingras, Y. 2010. Which scientific elites? On the concentration of research funds, publications and citations. Research Evaluation, 19(1).

[8] Masterson, K., \& Brainard, J. (2009). Private Gifts to Colleges Continued to Climb in 2008. Chronicle of Higher Education, 55(26), A15-A16.

[9] Newfield, C., 2010. Avoiding the Coming Higher Ed Wars. Academe, May/Apr2010, Vol. 96(3)

[10] Profiles of Engineering and Technology 2009 edition, 2010. American Society of Engineering Educators. Washington, DC.

[11] Psacharopoulos, G., 2008. Funding universities for efficiency and equity: research findings versus petty politics. Education Economics Vol. 16(3)

[12] Statistics. Accreditation Board for Engineering and Technology. Retrieved on November 25, 2010 from http://abet.org.

[13] Tandberg, D., 2010. Politics, Interest Groups and State Funding of Public Higher Education. Res High Educ 51:416-450. 